\title{
Repolitização da Gestão Educacional no Brasil: Estratégia de Gestão no Âmbito Público ${ }^{1}$
}

\author{
Repoliticization of Educational Management in Brazil: Management Strategy in \\ Public Scope
}

\section{Repolitización de Gestión Educativa en Brasil: Estrategia de Gestión en el Ámbito Público}

\author{
Katya Lacerda Fernandes' \\ 'Universidade Federal do Tocantins (UFT) - Palmas-TO. Brasil \\ E-mail: katyalacerda@uft.edu.br
}

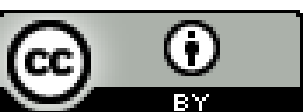

Educação: teoria e prática, Rio Claro, SP, Brasil - eISSN: 1981-8106

Está licenciada sob Licença Creative Common

\begin{abstract}
Resumo
O objetivo deste ensaio é problematizar a respeito da ressignificação da gestão, mediante a introjeção de um aparato conceitual e procedimental que reifica a lógica privada no interior da gestão pública. A partir da perspectiva do método materialista histórico-dialético, evidenciase os resultados parciais de uma pesquisa bibliográfica e documental, acerca dos desdobramentos da reforma estatal iniciada no final do século XX na orientação do processo de gestão municipal da educação na contemporaneidade. Ao apregoar a relação de unidadedistinção entre liberalismo, neoliberalismo e terceira via, conclui-se que a confluência entre gestão e gerencialismo expressa um processo de repolitização vinculado à proposta liberalcorporativa de redefinição do Estado, que estabelece, em suas bases, a reiteração da imbricação entre as noções de público e privado, o que implica a alteração do sentido do que seja gestão, direito e cidadania.
\end{abstract}

Palavras-chave: Estado. Políticas educacionais. Gestão educacional municipal.

\section{Abstract}

The objective of this assay is to problematize about the repoliticization of management, by introjection of a conceptual and procedural apparatus that reify private logic within the public management. From the perspective of materialist historical dialectical method, it's evidence the partial results of a research bibliographic and documentary, about the

\footnotetext{
${ }^{1}$ Este artigo representa a ampliação da discussão do trabalho intitulado: "Repolitização da Gestão Educacional no Brasil: A Lógica Privada no Aparato Público" publicado nos Anais do IV Seminário Internacional de Pesquisa do GREPPE realizado na Faculdade de Educação da Universidade Estadual de Campinas, de 06 a 08 de agosto de 2014.
} 
consequences of state reform initiated at the end of the 20th century in the orientation of municipal management process of education at the present. To proclaim the relationship of unity-distinction between liberalism, neoliberalism and third way, it's concluded that the confluence between management and managerialism expresses a repoliticization process linked to liberal corporate proposal redefinition of the State, establishing their bases the reiteration of interweaving between the notions of public and private, which implies changing at the sense of that be management, law and citizenship.

Keywords: State. Educational policy. Educational municipal management.

\section{Resumen}

El objetivo de este ensayo es problematizar sobre la repolitización de la gestión por la introyección de un aparato conceptual y procedimental que cosifica la lógica privada en el interior de la gestión pública. Desde la perspectiva del método materialista históricodialéctico, evidenciamos los resultados parciales de una investigación bibliográfica y documental, sobre las consecuencias de la reforma del Estado iniciadas a finales del siglo XX en la orientación del proceso de gestión municipal de la educación en la contemporaneidad. Al proclamar la relación de unidad-distinción entre liberalismo, neoliberalismo y tercera vía, se concluye que la confluencia entre la dirección y el gerencialismo expresa un proceso de repolitización vinculado en la propuesta liberal corporativa de redefinición del Estado, estableciendo sus bases de la reiteración de la imbricación entre las nociones de público y privado, lo que implica el cambio del sentido do que sea gestión, derecho y ciudadanía.

Palabras-clave: Estado. Políticas educacionales. Gestión educacional municipal.

\section{Introdução}

O objetivo deste artigo é polemizar a respeito do processo de repolitização da gestão educacional no Brasil, no interior do modo de produção capitalista. Para tanto, (i) segundo a análise de Coutinho (2006a; 2006b), partimos da existência de duas propostas de redefinição do Estado, de um lado, a liberal-corporativa, e, diametralmente, oposta a ela, a proposta democrática; (ii) abordamos o processo de redimensionamento da administração pública; E, por fim, (iii) identificamos que a proposição de um aparato conceitual e procedimental, juntamente com a ressignificação, tem na repolitização um papel fundamental para a reconfiguração das relações entre Estado e sociedade.

A compreensão do método materialista histórico-dialético permite situar o posicionamento que orientou a construção e interpretação dos resultados. Nessa perspectiva, inserimos os resultados parciais de uma pesquisa bibliográfica e documental, acerca dos desdobramentos da reforma estatal iniciada no final do século XX na orientação do processo de gestão municipal da educação nos primórdios do século XXI. 


\section{A redefinição do Estado: propostas e estratégias}

Para Coutinho (2006a), existem duas propostas de redefinição do Estado. A primeira, denominada de liberal-corporativa, ao representar os interesses da burguesia, consiste em desmantelar o pouco que há de público no Estado e submetê-lo às leis do mercado. Trata-se, portanto, do predomínio do privado sobre o público. Em contraposição, temos a proposta democrática que, ao representar os interesses das classes subalternas, centra-se na ampliação dos mecanismos de participação e socialização da política, e, consequentemente, na construção de uma sociedade de novo tipo, à sociedade socialista, única capaz de garantir o efetivo predomínio do interesse público.

A matriz liberal, historicamente, passou por metamorfoses e aprimoramentos que a levaram a assumir uma face neoliberal, que, na contemporaneidade, aparece transvestida de terceira via, que apesar de promover uma aparente crítica ao neoliberalismo, não propõe a superação do “controle sociometabólico do capital” (MÉSZÁROS, 2011, p. 30).

Essas alterações promovem mudanças no conteúdo, na forma e na organização do trabalho, porém não expressam uma mudança qualitativa no curso do projeto societário que subjuga a classe trabalhadora aos interesses da burguesia. Nesse sentido, existe uma relação de unidade-distinção entre liberalismo, neoliberalismo e terceira via.

Em linhas gerais, nos valemos de dois conjuntos complementares de análises. No primeiro, Behring e Boschetti (2010) apresentam a ideia de que para o liberalismo o mercado é um mecanismo natural de regulação das relações sociais, pressuposto que é cinicamente recuperado pelos neoliberais, em um contexto histórico muito diferente.

Nessa direção Lima (2008), ao discutir a finalidade do Estado para os liberais, o apresenta como mediador dos conflitos entre os grupos sociais e promotor do bem comum. Entretanto, evidencia a existência de uma reinterpretação neoliberal, na qual os liberais ortodoxos e os neoliberais não admitem a interferência do Estado, e, em outros casos, a defesa de um estado interventor, regulador, ou seja, um Estado conciliador.

No segundo bloco de interpretação Perry Anderson (2008, p. 9), ao realizar um balanço do neoliberalismo, inicia sua análise definindo-o como um fenômeno distinto do simples liberalismo clássico, caracterizando-o como "uma reação teórica e política veemente contra o Estado intervencionista e de bem-estar". 
Complementando o indicativo da existência de uma relação de unidade-distinção entre liberalismo, neoliberalismo e terceira via, destacamos o argumento de Silva (2011, p. 87) que assevera que a perspectiva da terceira via apesar de criticar o neoliberalismo, serve de "elemento articulador aos projetos de fortalecimento da concertação social e inviabilização de propostas contestadoras da ordem social capitalista".

Nessa linha de pensamento, o projeto liberal-corporativo analisado por Coutinho (2006b) possui, como expressão ideológica, o neoliberalismo em seus diferentes matizes. E é nesse sentido que Silva e Rodriguez (2013, p. 128), ao indicarem que a terceira via traz em sua estrutura a autopreservação do projeto neoliberal, o identifica como uma "estratégia capciosa de reconfiguração das orientações que não foram implementadas em sua plenitude pelo neoliberalismo".

Ressaltamos que identificar a unidade entre a proposta liberal, a neoliberal e de terceira via não elimina as diferenças existentes entre elas, situadas em contextos distintos e com formulações próprias. Para Giddens (2005, p. 80), "Os neoliberais querem encolher o Estado; os socialdemocratas, historicamente, têm sido ávidos para expandi-lo. A terceira via afirma que é necessário reconstruí-lo".

Porém, destacamos que, para Giddens (2001, p. 166), "Não há mais alternativas conhecidas à economia de mercado; a competição de mercado gera ganhos a que nenhum outro sistema pode se equiparar". Logo, “A esquerda deve se acostumar com os mercados, com o papel das empresas na criação de riqueza e com o fato de que o capital privado é essencial para o investimento social" (GIDDENS, 2001, p. 42).

Notamos, portanto, um alinhamento entre as referidas perspectivas ao lema thatcheriano do TINA (there is no alternative). Rechaça-se, nesse sentido, o papel das lutas de classes e fragmenta-se o conceito de Estado, decompondo-o em setores e grupos. Em ambas, apesar do contexto em que foram concebidas, é perceptível a cisão entre Estado e sociedade, diferentemente da proposta democrática de redefinição do Estado.

\section{A reforma do Estado como eixo da gestão no setor público}

Partimos do pressuposto de que a reforma do Estado, a reestruturação produtiva e, nos dizeres de Silva e Rodriguez (2013), o "neoliberalismo reconfigurado", e, mais 
especificamente, a maior aproximação do empresariado na orientação das políticas educacionais, são interfaces de uma mesma resposta do capital a sua crise estrutural.

A responsabilização do Estado pela crise é posta, no contexto da reforma, em detrimento do aspecto estrutural, constituinte do capital, como elemento gerador da redução das taxas de crescimento econômico e elevação das taxas de desemprego e inflação. Tal análise promove uma inversão que faz com que, no nível da aparência, a consequência do fenômeno seja apresentada como a sua causa.

Silva Jr. (2004, p. 66) salienta, coerentemente, que:

Com a universalização do capitalismo a partir da década de 1970 e a demanda estrutural por uma reorganização da sociedade civil, as reformas dos anos 1980 nos países de economia central e na década de 1990 nos países de economia periférica foram uma linha de continuidade dos múltiplos processos mercantis de espaços sociais outrora organizados segundo a racionalidade da esfera pública.

A reforma promovida pelo Estado, a partir de 1990, estabeleceu em suas bases a reiteração da imbricação entre as noções de público e privado. Isso pode ser verificado no Plano Diretor da Reforma do Aparelho do Estado (PDRAE) que definiu objetivos e estabeleceu diretrizes para a reforma da administração pública brasileira (BRASIL, 1995).

Em linhas gerais, a reforma do Estado significou a definição do papel do Estado “[...] deixando para o setor privado e para o setor público não estatal as atividades que não lhe são específicas" (BRESSER PEREIRA, 1997, p. 22), ou, em outros termos, objetivou "[...] transferir para o setor privado as atividades que podem ser controladas pelo mercado" (BRASIL, 1995, p. 12).

O PDRAE propôs a divisão do Estado em quatro setores, a saber: o núcleo estratégico, formado pelo Legislativo, Judiciário, Cúpula dos Ministérios e pelo Ministério Público; as atividades exclusivas, como regulamentação, fiscalização, segurança pública e seguridade social básica; os serviços não exclusivos, referentes a educação, saúde, cultura e pesquisa científica; a produção para o mercado, representado pelas empresas estatais (BRASIL, 1995).

Também, insere-se nessa discussão a definição de formas de propriedade, quais sejam: o núcleo estratégico, no qual a propriedade tem que ser necessariamente estatal; as atividades exclusivas de Estado, onde a propriedade também só pode ser estatal, pois é o lócus de exercício do poder extroverso de Estado; o setor não exclusivo ou competitivo do Estado, cuja propriedade ideal é a pública não estatal (BRASIL, 1995). 
Nesse sentido, o Estado do século XXI não será o Estado Social-burocrático, que entrou em crise, nem o Estado Neoliberal, que provou ser irrealista, mas se constituirá como um Estado Social-Liberal:

[...] social porque continuará a proteger os direitos sociais e a promover o desenvolvimento econômico; liberal, porque o fará usando mais os controles de mercado e menos os controles administrativos, porque realizará seus serviços sociais e científicos principalmente através de organizações públicas não estatais competitivas, porque tornará os mercados de trabalho mais flexíveis, porque promoverá a capacitação dos seus recursos humanos e de suas empresas para a inovação e a competição internacional (BRESSER PEREIRA, 1997, p. 18).

Concebido por Bresser Pereira (1997, p. 17) como "central para o desenvolvimento econômico e social, mas principalmente como um sócio, um agente catalizador e facilitador", o Estado Social-Liberal parte da combinação entre a visão social e a liberal, o que se apresenta com uma terceira via na condução das políticas.

Nessa lógica, é essencial para o bom funcionamento econômico e a consolidação dos regimes democráticos "[...] a combinação ou a complementaridade de mercado e Estado, de capital e organização, de empresários e administradores públicos e privados” (BRESSER PEREIRA, 1997, p. 11), cujo objetivo da intervenção é o estímulo e a preparação de empresas e do País para a competição generalizada.

Ao assentar-se nas dimensões institucional-legal, referente ao aparato regulatório; a cultural, calcada na assimilação do ideário gerencial, e na dimensão-gestão, voltada para a efetivação das ideias gerenciais sob o discurso da modernização e da qualidade, o PDRAE (BRASIL, 1995), como elemento estratégico de redefinição da administração pública, contribuiu significativamente para a repolitização.

Nesse sentido, as escolas, universidades, centros de pesquisa científica e tecnológica e as creches são concebidas como atividades competitivas, ou seja, "que podem ser controladas não apenas através da administração pública gerencial, mas também e principalmente através do controle social e da constituição de quase-mercados" (BRESSER PEREIRA, 1997, p. 25).

Temos, portanto, mediante o processo denominado de publicização, a defesa da “descentralização para o setor público não estatal” da execução das políticas públicas, pois estas não envolveriam o exercício do poder de Estado, pois “[...] transfere-se para o setor público não estatal a produção dos serviços competitivos ou não exclusivos de Estado, estabelecendo-se um sistema de parceria entre Estado e sociedade para seu financiamento e controle" (BRASIL, 1995, p. 13). 
Importa indicarmos que, apesar das orientações do PDRAE focalizarem sua atenção no âmbito federal, estas não podem ser destacadas dos níveis estadual e municipal, constituintes da administração pública, pois, ao separar a direção das políticas de sua execução, se desconcentra atribuições para o âmbito local (BRASIL, 1995).

Em suma, a administração pública gerencial, ao ter em seu ideário que os serviços sociais e científicos são atividades competitivas, as concebe em composição ao "setor onde o Estado atua simultaneamente com outras organizações públicas não estatais e privadas" (BRASIL, 1995, p. 41), reafirmando, portanto, a regulação social mercantil nas relações sociais.

\section{O Gerencialismo como aparato privado no interior da Política Pública Educacional}

Especificamente no âmbito da educação, tratar das questões relativas à gestão enseja, mesmo que brevemente, retomar o significado do que seja gestão. Segundo Gracindo e Kenski (2001, p. 113, grifos das autoras), os termos gestão e administração da educação são utilizados ora como sinônimos, ora como termos distintos. Nesse sentido:

\footnotetext{
Algumas vezes, gestão é apresentada como um processo dentro da ação administrativa; em outras, seu uso denota a intenção de politizar essa prática. Apresenta-se também como sinônimo de 'gerência', numa conotação neotecnicista, e, em discursos mais politizados, gestão aparece como a 'nova' alternativa para o processo político-administrativo da educação.
}

No interior dessa disputa semântica temos, por parte do Banco Mundial e das políticas por ele ditadas via acordos internacionais, a adoção do "termo gestão como sinônimo de gerência, como processo instrumental através do qual fica garantida a implementação dessas políticas" (GRACINDO; KENSKI, 2001).

É sob as bases desse entendimento, conforme Gracindo e Kenski (2001, p. 113), que se pode "compreender a disseminação, os largos incentivos e fartos financiamentos para a implantação de processos de 'gerência total' ou 'qualidade total' nos diversos níveis de ensino e nas diversas instâncias do Poder Público”. Noutra perspectiva, muitos educadores utilizam a expressão gestão da educação “[...] como uma reação à forma descomprometida, 'neutra', tecnicista e mantenedora da realidade vigente". 
Nesse sentido, Montaño (2003, p. 192) apregoa que “enquanto a 'gestão' refere-se a processos tanto administrativos como decisórios (políticos) da atividade, a racionalidade neoliberal reduz este conceito ao de 'gerência', apenas ligado à administração dos fundos e da execução".

Assim, consoante à perspectiva mercantil, a gestão identifica-se com o gerenciamento, logo, deve ser caracterizada por uma administração gerencial; enquanto em uma abordagem mais ampla, a gestão refere-se a um todo estruturado que abarca desde a formulação das políticas até a avaliação do executado, para além de uma participação restrita, calcada na operacionalização de tarefas.

Insere-se, nesse contexto, a repolitização da gestão educacional, que se caracteriza pela confluência entre gestão e gerencialismo, bem como, dentre outros aspectos, pelo empreendimentismo, que, para Harvey (2013, p. 161):

[...] caracteriza não somente a ação dos negócios, mas domínios da vida tão diversos quanto a administração municipal, o aumento da produção do setor informal, a organização do mercado de trabalho, a área de pesquisa e desenvolvimento, tendo até chegado aos recantos mais distantes da vida acadêmica, literária e artística.

O empreendimentismo, que passa a nortear a administração pública, configura-se, desse modo, como parte da gestão municipal da educação, por meio do processo de redimensionamento entre Estado e Sociedade, marcado por competição, controle, desconcentração e imbricação entre a gestão gerencial e a gestão democrática.

Sob a lógica do neoconservadorismo neoliberal ou de sua atual vertente, a terceira via, ampliou-se a lógica do privatismo e do individualismo, além da introjeção de um aparato conceitual e procedimental (gerencial) que reifica a lógica privada no interior da gestão pública. Nesse sentido, a ressignificação exerce um papel fundamental para a repolitização da gestão em seus diferentes âmbitos, no qual:

[...] 'direito' vira sinônimo de 'privilégio' dos indolentes, sujeito de direitos vira
'usuário de serviços' destruição social vira 'reforma', cidadania vira 'mera
participação numa comunidade qualquer', solidariedade vira filantropia,
desempregado vira 'indivíduo com baixa empregabilidade' e parceria vira ação em
que a iniciativa privada entra com a 'iniciativa' e o poder público com os fundos
(ARANTES, 2000, p. 16).

Trata-se, no geral, da introdução de mudanças organizacionais e culturais à administração pública, para torná-la gerencial. Nessa linha de pensamento, também é possível afirmar que:

[...] capacitação de professores foi traduzida como profissionalização; participação da sociedade civil como articulação com empresários e ONGs; descentralização como desconcentração da responsabilidade do Estado; autonomia como liberdade de

Educação: Teoria e Prática/ Rio Claro/ Vol. 25, n.50/ p. 453-465/ Set.-Dez. 2015. 
captação de recursos; igualdade como equidade; cidadania crítica como cidadania produtiva; formação do cidadão como atendimento ao cliente; a melhoria da qualidade como adequação ao mercado e, finalmente, o aluno foi transformado em consumidor (SHIROMA; MORAES; EVANGELISTA, 2002, p. 52).

Destacamos, nesse contexto, a imbricação entre os princípios que regem a reforma administrativa do Estado e as políticas educacionais. A partir dessa articulação, afirmarmos, conforme Silva Jr. (2004, p. 81), que "O papel político da municipalização da educação brasileira é, pois, constituir-se em espaço social para a realização do novo pacto social [...]” orientado por um "novo paradigma político".

Presenciamos, nos primórdios do século XXI, a retomada de vários mecanismos que perpassam a lógica privada de delimitação da área de atuação do Estado tais como: a publicização, a terceirização, a desconcentração e as parcerias público-privadas, que representam um aspecto essencial na reconfiguração do papel do Estado.

Temos, sob os ditames da terceira via, a repolitização da gestão associada ao reordenamento político, econômico e cultural da sociedade. Assim, ganham centralidade as parcerias público-privadas e a ideia do público não estatal. Destarte, o Estado passa a propalar seu papel regulador e orientador das políticas de modo a promover a responsabilização dos indivíduos e de suas Organizações Não Governamentais (ONGs).

Fernandes e Lagares (2014), ao discutirem essa questão, evidenciam a articulação da ampliação da lógica privada e de ONGs no âmbito educacional ao próprio processo de reconfiguração do capitalismo. Nesse sentido:

[...] a transposição do ideário mercadológico para as escolas e órgãos administrativos, [...] caracteriza o quase mercado educacional e o gerencialismo. Atrelado ao referido contexto é que ocorre, articuladamente, a expansão em secretarias estaduais e municipais da parceria público-privada, a desqualificação da formação docente realizada pelas universidades públicas e a introjeção da competição entre as escolas (FERNANDES; LAGARES, 2014, p. 11).

Retomamos, portanto, o nexo entre o neoliberalismo e a terceira via, marcado pelo imperativo de "eliminar toda e qualquer política estatal que imobilize os indivíduos, gere obstáculos à expansão do mercado e crie dificuldades para o pacto entre capital e trabalho" (LIMA; MARTINS, 2005, p. 58).

Para Silva Jr. (2004, p. 72), no caso específico da reforma da educação, de sua implantação e da mudança da sociedade civil, "a municipalização desconcentradora joga um peso muito forte na reconfiguração dessa sociedade civil e na sedimentação do novo pacto social". 
Nesses termos, Silva Jr. (2004, p. 59), ao tratar do papel político da municipalização educacional na construção dos novos traços da sociedade civil na década de 1990, evidenciou que:

[...] de um lado, a municipalização possibilita uma autonomia aparente para o município e transfere o fazer educacional do Estado no âmbito da União para essa esfera. De outro, e no mesmo movimento, repassa deveres do Estado com os direitos sociais subjetivos do cidadão para a sociedade civil, tendo como uma das instituições centrais a escola, cujo modelo de organização e forma de gestão são concretizados [...] pelo que se denominou, de forma centralizada, 'municipalização'.

Nessa linha de pensamento, também, apregoa-se que a gestão privada é indicada como a que tende a ser a mais adequada, quando acompanhada por um "seguro sistema de regulação" (BRASIL, 1995, p. 44).

Sob a lógica da gestão gerencial, a responsabilização dos gestores municipais pela qualidade do ensino, insere-se em um movimento que, por seu caráter opaco, nas relações sociais capitalistas, não revela a profundidade das desigualdades em que se inserem os 5.565 municípios brasileiros, conforme número do Atlas do Censo Demográfico do IBGE de 2010 (IBGE, 2013).

No geral, a perspectiva liberal-corporativa, ao possibilitar a pseudoidentificação entre a gestão gerencial e a gestão democrática, as toma como funcionais à lógica do capital, o que evidencia a repolitização da gestão educacional pública a um aparato político-técnico de introjeção da lógica privada.

\section{5. À guisa de conclusão}

Ao apregoar a relação de unidade-distinção entre liberalismo, neoliberalismo e terceira via, evidenciamos que o processo de repolitização, vinculado à proposta liberalcorporativa de redefinição do Estado tem, entre suas expressões, a confluência entre gestão e gerencialismo em detrimento da proposta democrática voltada para o interesse público.

Vale esclarecer que não se trata de um processo de despolitização, pois as relações sociais possuem uma intencionalidade constitutiva, não neutra. Logo, entendemos a repolitização da gestão como um movimento indissociável do processo de reordenamento político, econômico e cultural da sociedade.

A reforma estatal em curso, cujos pressupostos foram inicialmente expostos no PDRAE (BRASIL, 1995) propala para o âmbito público a adoção da administração gerencial, 
que é perpassada pela imbricação entre público e privado, presente na ideia de acabar com o monopólio do Estado sobre o público, evidenciado no conceito de público não estatal.

Esse movimento de repolitização da gestão educacional é funcional à nova face do neoliberalismo, a terceira via, pois pressupõe a realização da lógica do mercado e sua ênfase no indivíduo, no empreendimento e na competição. Assim, a desconcentração, que caracteriza a municipalização brasileira, estabelece uma forma sutil de regulação social, calcada no gerencialismo.

Diante do exposto, constatamos que a reforma do Estado trouxe implicações para a gestão municipal da educação, em um contexto de redimensionamento das relações entre Estado e sociedade, mediante adoção da administração pública gerencial, do empreendimentismo e do estabelecimento de parcerias público-privadas. Assim, o paradigma gerencial contemporâneo tem fortalecido a tradição municipalista brasileira, que vem desde o período colonial, com a crescente responsabilização dessas unidades subnacionais na área social.

A repolitização da gestão educacional no Brasil, como estratégia de gestão no âmbito público, tem como arcabouço, nos primórdios do século XXI, a orientação política da terceira via, que frente à opacidade do real, ficou mimeticamente incrustrada à reforma estatal dos anos 1990, por pressupor, fundamentalmente, o redimensionamento das relações entre Estado estrito e sociedade.

Em síntese, na contemporaneidade, a proposição de um aparato conceitual e procedimental, juntamente com a ressignificação, tem na repolitização um papel fundamental para a reconfiguração das relações sociais e o estabelecimento da proposta liberal-corporativa. Assim, dentre outros termos, altera-se o sentido do que é público, do que seja gestão, direito e cidadania.

Compete-nos, portanto, questionar e lutar contra os interesses da classe hegemônica, por uma democracia socialista, pois, conforme Marx (2013, p. 80) "a sociedade atual não é um cristal inalterável, mas um organismo capaz de transformação e em constante processo de mudança”.

\section{Referências}

ANDERSON, P. Balanço do neoliberalismo. In: SADER, E.; GENTILI, P. (Orgs.). Pósneoliberalismo: as políticas sociais e o Estado democrático. 8 ed. Rio de Janeiro: Paz e Terra, 2008. p. 9-23.

Educação: Teoria e Prática/ Rio Claro/ Vol. 25, n.50/ p. 453-465/ Set.-Dez. 2015. 
ARANTES, P. E. Esquerda e direita no espelho das ONGs. In: Cadernos ABONG. ONGs, identidade e desafios atuais. São Paulo: Autores Associados, v. 1, n. 27, p. 3-27, mai. 2000.

BEHRING, E. R.; BOSCHETTI, I. Política social: fundamentos e história. 7 ed. São Paulo: Cortez, 2010.

BRASIL. Ministério da Administração e Reforma do Estado. Plano diretor da reforma do aparelho de Estado. Brasília: MARE/Imprensa Nacional, 1995.

BRESSER PEREIRA, L. C. A reforma do Estado dos anos 90: lógica e mecanismos de controle. Brasília: Ministério da Administração Federal e Reforma do Estado, 1997.

COUTINHO, C. N. O Estado brasileiro: gênese, crise e alternativas. In: LIMA, J. C. F.; NEVES, L. M. W. (Orgs.). Fundamentos da educação escolar do Brasil contemporâneo. Rio de Janeiro: Fiocruz/EPSJV, 2006a. p. 173-200.

COUTINHO, C. N. Intervenções: o marxismo na batalha das ideias. São Paulo: Cortez, $2006 b$.

FERNANDES, K. L.; LAGARES, R. Projeto societário e educação: a gestão educacional na primeira década do século XXI. In: CONGRESSO IBERO-AMERICANO DE POLÍTICA E ADMINISTRAÇÃO DA EDUCAÇÃO, 4., CONGRESSO LUSO BRASILEIRO DE POLÍTICA E ADMINISTRAÇÃO DA EDUCAÇÃO, 7., 2014, Porto. Anais... Porto: IPP, 2014. p.1-13. Disponível em: < http://anpae.org.br/IBERO_AMERICANO_IV/GT5/GT5_Co municacao/KatyaLacerdaFernandes_GT5_integral.pdf>. Acesso em: 20 fev. 2014.

GIDDENS, A. A terceira via e seus críticos. Rio de Janeiro: Record, 2001.

GIDDENS, A. A terceira via: reflexões sobre o impasse político atual e o futuro da socialdemocracia. 5 ed. Rio de Janeiro: Record, 2005.

GRACINDO, R. V.; KENSKI, V. M. Gestão de sistemas educacionais: a produção de pesquisa no Brasil. In: WITTMANN, L. C.; GRACINDO, R. V. (Coords.). O estado da arte em política e gestão da educação no Brasil: 1991 a 1997. Brasília/Campinas: ANPAE/Autores Associados, 2001. p. 113-126.

HARVEY, D. Condição pós-moderna. 24 ed. São Paulo: Edições Loyola, 2013.

INSTITUTO BRASILEIRO DE GEOGRAFIA E ESTATÍSTICA - IBGE. Atlas do Censo Demográfico 2010. Rio de Janeiro: IBGE, 2013. 
LIMA, A. B. de. Estado, políticas e educação no Brasil. In: LUCENA, C. (Org.). Capitalismo, Estado e educação. Campinas: Alínea, 2008. p. 133-150.

LIMA, K. R. de S.; MARTINS, A. S. Pressupostos, princípios e estratégias. In: NEVES, L. M. W. (Org.). A nova pedagogia da hegemonia. São Paulo: Xamã, 2005. p. 43-67.

MARX, K. O Capital: crítica da economia política. Livro I - O processo de produção do capital. Tradução de Rubens Enderle. São Paulo: Boitempo, 2013.

MÉSZÁROS, I. Para além do capital: rumo a uma teoria da transição. Tradução de Paulo Cezar Castanheira e Sérgio Lessa. São Paulo: Boitempo, 2011.

MONTAÑO, C. Terceiro setor e questão social: crítica ao padrão emergente de intervenção social. 2 ed. São Paulo: Cortez, 2003.

SILVA, D. P.; RODRIGUEZ, Vicente. A política educacional brasileira no contexto do gerencialismo contemporâneo. In: VII SEMINÁRIO SOBRE "A PRODUÇÃO DO CONHECIMENTO EM EDUCAÇÃO” - Política educacional do século XXI: paradoxos, limites e possibilidades, 7., 2013, São Paulo. Anais... São Paulo: PUC/Campinas, 2013. p. 125-132.

SILVA, D. P. Planejamento e gestão escolar: concepções e implicações. 2011. $100 \mathrm{f}$. Dissertação (Mestrado em Educação) - Pontifícia Universidade Católica de Goiás, Goiânia, 2011.

SILVA JUNIOR, J. dos R. O papel político da municipalização educacional na construção dos novos traços da sociedade civil na década de 1990. In: MARTINS, A. M.; OLIVEIRA, C. de; BUENO, M. S. S. (Orgs.). Descentralização do Estado e municipalização do ensino: problemas e perspectivas. Rio de Janeiro: DP\&A, 2004. p. 57-83.

SHIROMA, E. O.; MORAES, M. C. M. de; EVANGELISTA, O. Política Educacional. 2 ed. Rio de Janeiro: DP\&A, 2002.

Recebido em: 26/02/2015

Aprovado para publicação em: 08/09/2015

Publicado em: 22/12/2015 